\title{
Genre Expectations and Viewer Reaction to Our Planet: Are Audiences Motivated to Act More Sustainably?
}

\author{
CLAIRE AHN \\ Queen's University
}

\begin{abstract}
As more people turn to documentaries to learn about environmental issues it becomes even more important to consider the ways in which genre and its representational patterns, such as the use of images, affect viewers. Re-examining the multiliteracies framework and grounded in rhetorical genre studies, this paper explores the first two episodes of Our Planet, a Netflix docu-series that catalyzed strong responses based on two jarring image sequences. The purpose of this paper is to examine how our familiar understandings of particular genres impacts our understanding of particular issues and what happens when the familiar patterns of a genre are challenged.
\end{abstract}

\section{Introduction}

In their iconic paper The New London Group (1996) introduced the term multiliteracies. The purpose of this concept was to "describe two important arguments we might have with the emerging cultural, institutional, and global order: the multiplicity of communications channels and media, and the increasing saliency of cultural and linguistic diversity" (p. 63). At the time, the authors observed the significant shift in the role schools played and how "cultural and linguistic diversity [were] central and critical issues, [and] as a result the meaning of literacy pedagogy has changed" (pp. 68-69). The initial observations that The New London Group made in the 1990s still hold true today, and are arguably even more significant now than ever before. Since the publication of their paper, though, there are apparent gaps in what types of literacies should be considered, beyond technology. Luke (2015) noted that what is now required is a reframing of literacies to include more diverse perspectives and also larger issues such as those related to the environment. Orr (1990) suggests seven key principles needed to develop ecological literacy, one of which is acknowledging that "all education is environmental education" and that "environmental issues are complex and cannot be understood through a single discipline" (p. 49). There are indeed multiple literacies that are required to understand the symbiotic relationship of nature, to understand the larger issues, and to consider sustainable solutions. However, Orr and other environmental educators and scholars tend to focus on the traditional approaches to developing ecological literacy, which primarily include outdoor education but also include implementing more traditional texts such as novels or textbooks. Yet, as The New London Group observed, there was a shift in engaging with literacy and text such that people were engaging in multiple modes of meaning-making. The authors further observed that in many instances "the visual mode of representation may be much more powerful and closely related to language than 'mere literacy' would ever be able to allow" (p. 64). In the current context, media genres play a powerful role in influencing viewers' awareness and understanding of particular environmental issues and the visual images make a lasting impact. Our understanding of "literacy" and "texts" today 
are much broader and more complex. It is no longer, simply, about reading and writing in the "traditional" sense. Thus, it is significant to consider and explore how people interact with multiple literacy practices, how information is mediated across different platforms, and to consider how it affects learning and understanding, especially around critical issues such as with the environment.

Attention to and concerns about the current state of the environment have been ongoing. So much so that in April 2016, on Earth Day, the Paris Agreement, part of the United Nations Framework Convention on Climate Change and the world's first climate change agreement, was opened for signature. By the following year, 189 nations had become party to it. The Paris Agreement outlines a commitment for countries to limit the increase in average global temperature to below $2^{\circ} \mathrm{C}$ above pre-industrial levels, to provide aid to developing nations to combat climate change, to reduce greenhouse gases, and to set a goal to be carbon neutral by the year 2050. At the United Nations Climate Action Summit in Washington, DC two weeks after the opening of the Paris Agreement, former United Nations Secretary-General Ban Ki-Moon stressed the need to act now:

Temperatures continue to climb. Arctic sea ice is melting fast. . . . It is time to take climate action to the next level. We need to accelerate the speed, scope and scale of our response, locally and globally... . Today as never before, the stars are aligning in favour of climate action. (Ban, 2016)

While world leaders and various scientific and grassroots organizations continue to express deep concern for the state of our planet and are working on possible solutions, educating the general public about current and future realities is a particular challenge. Much of the information the public receives about the environment is through the media. UNESCO (1997) notes the significant role media has in appealing to the public to act in sustainable ways. Others also remark upon the increase in environmental communication and, more specifically, the role visual images play on people's awareness of environmental issues. The documentary genre, in particular, seems to be a lasting, popular choice as a text among the general public (Kara \& Marcus, 2016). In the contemporary moment, environmental issues are of significant concern. However, corporate media often either remain silent so as not to frighten viewers (Duvall, 2017) or rely heavily on business or political rhetoric, resulting in viewers not listening or even caring (Boykoff, 2007; Nissani, 1999; Swain, 2012). Nevertheless, in recent decades, there has been a significant increase in the production and distribution of environmental documentary films (Duvall, 2017).

Viewers watch documentaries out of a desire to learn, which then can have an impact on their actions or raise their awareness about an issue (Duvall, 2017; Nichols, 2010). Further, notes Duvall (2017), the "documentary film enjoys a privileged status as a mediated representation of reality compared to fiction films" (p. 8). Historically, early innovators in cinema were scientists who wanted to document events and actions, and it was in their work that "the documentary film had prenatal stirrings" (Barnouw, 1993, p. 3). Eadweard Muybridge, who was commissioned to document the gait and speed of horses, introduced the illusion of motion by presenting photos of horses in quick succession at various speeds to simulate a horse galloping. Muybridge "foreshadowed a crucial aspect of the documentary film: its ability to open our eyes to worlds available to us but, for one reason or another, not perceived" (Barnouw, 1993, p. 3). To add, images used in documentary films are viewed as reflections of an event or of people (Barthes, 1981). This is what Nichols (2010) refers to as the indexical quality of the image, the ways in which an 
image "bears a strict correspondence to what it refers to" (p. 34). According to this line of thought, the so-called reality of the image draws a desire to know (Hill, 2004; Nichols, 2010) and an emotional response from the viewer, which makes it more persuasive (Hill, 2004). It is worth noting that all documentaries are rhetorical because they present audiences with a specific point of view (Murray \& Heumann, 2014) and offer the "best available means of persuasion in a given situation" (Hackley, 2012, p. 4). Environmental documentaries implement a variety of rhetorical modes, such as oral narration and the use of music, which also act persuasively on audiences. But the nuanced play of visual images and the purposeful use of certain kinds of visuals in environmental documentaries can have a powerful impact in shaping people's perceptions and understanding of environmental issues (Cox, 2013). With regards to literacy then, as more and more people turn to documentaries to learn about significant issues, it is worth considering other forms of literacy, such as how visual images impact the meaning-making process. The kinds of images implemented, or visual rhetorical modes used, are also part of the common patterns utilized in documentaries and are expected by viewers. As such, it is also important to consider the text itself. That is, in what ways do particular texts or genres and its patterns affect viewer responses? Specifically, most people nowadays are turning to media formats that utilize various modes to distribute information and knowledge, much of which tend to rely on visual images. Thus, it is important to continue to expand our notions of "literacy" and "text," especially in relation to the dissemination of significant issues, and also to consider more deeply the impact of genres. To begin, this paper is grounded in rhetorical genre studies or the idea that genre is a form of social action (Miller, 1984) and will centre on the textual regularities or genre patterns, specifically on visual rhetorical modes. The last section of the paper will apply theoretical frameworks by analyzing the first two episodes of the Netflix docuseries Our Planet (Clay, Huertas, Anderson, \& Fothergill, 2019), which generated favourable audience response but also catalyzed discussions due to strong viewer reactions that draws attention to and questions whether viewers were simply reacting to the images or the genre (docuseries) and its use of patterns (visual rhetorical modes).

\section{Rhetorical Genre Studies}

Genre studies, in general, provide systematic and inclusive rules for classifying and defining texts. The development of rhetorical genre studies (RGS) includes Miller's (1984) positioning and definition of genre as a form of social action or looking at "the roles that genres play in how individuals experience, co-construct, and enact social practices and sites of activity" (Bawarshi \& Reiff, 2010, p. 59). Rhetoric, in an RGS approach, is connected to context (Bitzer, 1968; Miller, 1984). For example, considering the history of the documentary that started with Muybridge, as described above, the genre has shifted based on people's interest and historic events. One only needs to look at the start of World War II, which catalyzed the development of documentary forms (McLane, 2012) and, specifically, the use of propaganda (Barnouw, 1993). After the war was over, documentaries shifted to focus on topics of rebuilding nations (McLane, 2012). This included documentaries that centred on subjects like the Nuremberg trials (Barnouw, 1993), but also included films offering themes of beauty and peace, such as Arne Sucksdorff's (1941) A Summer's Tale, which depicted idyllic natural environments. The topics shifted according to events and public interest and, consequently, the genre template 
also shifted. With the documentaries about the Nuremberg trials, much of the footage included unused and newly discovered footage from the homes of Nazi officers. This "wide use of photographic evidence [during the trials] was apparently without precedent" (Barnouw, 1993, p. 175). Today, these types of images are used frequently and often referred to as "found footage."

While the general structure of the documentary genre stayed the same, they are also "inherently dynamic rhetorical structures that can be manipulated according to the conditions of use" and have the ability to vary and be responsive to the reader or viewer (Bawarshi \& Reiff, 2010, p. 477). A genre does not remain rigid; while the structure of the documentary, for example, remains relatively static, it adapts according to a number of contextual elements including time, circumstances, the motivation of the director, and technological advancements. According to Schryer (1994), genres are "stabilized for now" (p. 107) in that they provide familiar structures and guidelines, but are also adaptable, depending on the context. Rhetorical forms are "socially learned and hence represent conventionalized patterns-for-thought," which have the power to create meaning and "to affect beliefs, attitudes, and values because they arise out of social reality" (p. 140). Miller (1984) contests that "an understanding of genre can help account for the way we encounter, interpret, react to, and create particular texts" (p. 23). Specific representational patterns of a particular genre are socially constructed and inherently learned, and are often traits we come to expect with certain genres and even subgenres. Depending on the type of environmental documentary, for example, these patterns often include the narrative structure, the omniscient voice-over, reliance of scientific evidence, interview of an expert, and found footage. The form or representational patterns of environmental documentaries must be considered in relation to social context because it is these "patterns of arrangement which are given a rhetorical force by their habitual use and codifiability" (Gronbeck, 1978, p. 140); these patterns include visual rhetorical modes.

\section{Visual Rhetorical Modes}

Rhetoric has a constitutive action in that "the purposeful use of language ... helps to shape our perception of the world itself" (Cox, 2013, p. 63). Today, the understanding of "language" and "literacy" is much broader and includes different modes, such as visual images. Focusing on visuals begs the question, as Hill (2004) posits, "How exactly do images persuade? How do images work to influence the beliefs, attitudes, opinions - and sometimes actions - of those who view them?" (p. 25). Part of this includes the indexicality of the image, as outlined earlier, and also the vividness, which refers to how some images are more vivid than others; statistics presented on graphs are less vivid and thus less rhetorically effective than moving and evocative images that reflect experiences viewers may be able to relate to (Hill, 2004). The repetitious presentation of the same or similar images also has a more persuasive effect (Cox, 2013; Hansen \& Machin, 2013; Helmers \& Hill, 2004; Hill, 2004) and can result in images being more memorable (Helmers \& Hill, 2004; Joffe, 2008; Smith \& Joffe, 2012; O’Neill \& Nicholson-Cole, 2009). Images have the capacity to elicit complex emotions while also portraying abstract values or ideas that are difficult to represent linguistically (Hill, 2004). Ultimately, images may help people understand and connect to complex ideas related to the environment because they are vivid and salient (O’Neill \& Nicholson-Cole, 2009). 
With regards to visual rhetorical modes, then, they are not limited to one media format, for example, but are utilized and seen in different genres and can impact viewers in various ways, especially when it comes to issues of the environment (Ahn, 2018; Ahn, 2020). It is worth noting that the use of some visual rhetorical modes is related to specific genres of environmental documentaries. For example, docuseries such as The Blue Planet or Planet Earth are often associated with narrator Sir David Attenborough, so most will assume, based on his past films and series, that the images will include beautiful landscapes and animal interactions. These types of films often employ sublime visual rhetoric, where the images help to develop a deeper awareness (Cox, 2013) and often invite viewers to consider the beauty of nature and what might be lost should people not change their attitudes and behaviours. Other documentaries, such as those directed and produced by Louis Psihoyos, often employ images that would likely be described as being disturbing. One such example is The Cove (DuPré \& Psihoyos, 2009). The majority of the documentary follows Psihoyos and his crew trying to record fishermen illegally luring, trapping and killing dolphins in a cove. The images of the latter are grotesque and very disturbing and oftentimes viewers are upset by such images and tend to turn away. Yet, if one is familiar with Psihoyos' films, one might expect those types of images and thus choose to avoid his documentary films. When considering how a text or specific genre is used to inform the public about specific issues, it is significant to consider how viewers respond to their expectations of the genre and its representational patterns such as the use of visual rhetorical modes, and if this impacts their understanding of environmental issues and their wiliness to act or change. What follows is an analysis and discussion of two episodes in the most recent Netflix docuseries, Our Planet, where viewers' reactions were particularly strong in response to two image sequences. The questions that arise from reviewing audience reactions are whether they were responding to the images themselves or whether their expectation of the genre was disrupted. The larger, follow up question also is what effect did this have, if any, on viewers' motivation to act in more sustainable ways.

\section{The Unexpected Outcome of Our Planet}

On April 5, 2019, Netflix released Our Planet, an eight-episode docuseries providing viewers with an opportunity to "experience our planet's natural beauty and examine how climate change impacts all living creatures" (Netflix, Our Planet). There was an enthusiastic response immediately after the release, even with viewers having watched only the first episode, "One Planet." On Twitter, many viewers commented on the visual images, and how it is "so beautiful," "brilliantly shot," and provides "amazing storytelling, breathtaking footage and is an important message" (OurPlanet, 2020). Similarly, another commented that the "creativity, passion and education [is] brought together in a stunning way. [Our Planet] is the perfect example of storytelling [to change] the way we see the world (OurPlanet, 2020).

Reviewers of this series have commented that it is the first of its kind to effectively braid together striking and evocative images, while at the same time addressing issues of climate change. Our Planet producer Alastair Fothergill notes: "the time had come to try and do a series which would be as entertaining and accessible as series like Planet Earthbut for the first time deal in-depth with the challenges that our planet faces . . there's no doubt that it is seriously under threat. And we felt that it was a story that urgently needed telling now" (Shapiro, 2019, para. 5). Similar criticisms have been raised with previous 
docuseries such as Planet Earth or Frozen Planet, with the main crux of the argument being that issues of climate change just seem to be tagged on at the end (Yong, 2019a). Our Planet is unique in that "it does what no other natural-history documentary has done. It forces viewers to acknowledge their own complicity in the destruction of nature, in the moment. It feels so sad, but also right" (para. 10; emphasis in original).

The opening episode of the series, "One Planet," serves as a prologue of sorts, starting with the image of the Earth, which is of great significance. This image in the opening scene of the series mirrors one of the first images of Earth taken from space, later titled "Earthrise," and has become one of the most "influential photographs ever taken" (NASA, 2012, para. 19). According to Kitchell (2012), this image was the "consciousness changer" with regard to the use of images in promoting environmental awareness. The juxtaposition of the blue and green Earth against the grey moon helped viewers to realize the importance of protecting the Earth (Kitchell, 2012). Images are used to represent complex issues, "to awaken public consciousness over misuse of the environment," and as a method of "communication to create and reinforce the message" (Gold \& Revill, 2004, p. 3). Right away, Our Planet begins to situate the viewer to consider their own role in and impact on the current state of the environment, with just a simple image of the Earth. The episode moves on to provide a glimpse of different landscapes and habitats: the Peruvian seacoast, oceans and deserts, the plains of Africa, rainforests, boreal forests, Antarctica, the Arctic, and Greenland. After this introduction to the series, the next seven episodes focus on specific areas of the world and are titled accordingly: "Frozen Worlds," "Jungles," "Coastal Seas," "Deserts to Grasslands," "High Seas," "Fresh Water," and "Forests." For the purpose of this paper, the discussion will focus on the first two episodes, "One Planet" and "Frozen Worlds," with attention to two specific scenes in each episode.

Overall, the images in both episodes are indeed brilliant, and what one might expect from such a production. In "One Planet," some of the images include: a bright array of swimming fish; typical close-up shots of vibrant hummingbirds seeking nectar from various flowers demonstrating the symbiotic relationship nature depends on; a tiger stealthily weaving in and out of grass; and, of course, the obligatory image of a polar bear (albeit not on an ice floe). Right away, most viewers would be enamoured with the images, realizing or perhaps re-realizing the beauty of our planet, as demonstrated in some of the comments mentioned earlier. The images throughout the second episode, "Frozen Planet," are equally striking: penguins and narwhales swimming gracefully, majestic glaciers towering over the ocean, and humpback whales working synchronously to entrap and feed on krill. These types of visual scenes would be considered to draw upon sublime visual rhetoric, where the images help to develop a deeper awareness (Cox, 2013) and, consequently, invite viewers to consider the beauty of the world. Many of the images seen in the series as a whole are very similar to other productions narrated by Attenborough where "nature is still mostly shown as pristine, and the presence or impacts of people on the natural world very seldom appear" (Jones et al., 2019, p. 420). Many who are familiar with documentaries featuring Attenborough have learned to come to expect a specific kind of theme and tone to the films and consequently also the kinds of images. Yet, there is one scene in the first episode, "One Planet," that viewers expressed more empathy for, and a bit more shock than others.

About a third of the way into the first episode, viewers are introduced to a flock of flamingos, focusing on the baby chicks (flamingets) that have recently hatched and the 
need for all the flamingos to migrate to another source of water. However, some of the flamingets cannot keep up with the other birds as they move across the fields of evaporated salt from dried-up water sources and, as salt builds up and solidifies on their legs, they are eventually delayed to the point where they are immobilized. It is indeed a heart-wrenching scene as we see a tiny flamingo struggling to even walk, doing its best to stumble along its way. As viewers, we only hope that the flaminget was able to make it, even though deep down we know this is likely not the case. In response to this scene, viewers commented that "this scene in \#OurPlanet [and] I'm an absolute mess" and "the baby flamingo with the salt [around] its legs on Our Planet was too much", and one viewer simply stated "that poor baby flamingo with salt legs" (OurPlanet, 2020). One viewer also remarked: "please tell me that someone from the crew helped this baby flamingo with solidified salt on its teeny-weeny legs. Or, I'll lose all faith in humanity" (OurPlanet, 2020). Many other comments reflect similar sadness and some stated they even had to stop watching the episode. The question, though, is why did this image in this episode, in particular, garner such a jarring effect? Throughout the episode, viewers also see typical hunting scenes of wildebeests being chased by wild dogs or wolves chasing and hunting caribou in the boreal forests, or even lone animals wandering through dry desert plains in search of water. Is it because viewers are not exposed to the actual killing of the animals, or is it because these types of scenes have become normalized in so many other kinds of environmental documentaries? Is it because as viewers we tend to have more sympathy for baby animals we might categorize as being "cute"? The larger question is, do these types of images or reactions convince people to act in more eco-conscious ways? Some viewers ask about the state of the flamingo after filming this scene, and some do note the importance of the natural world, of humanity's impact, and the need to do better. But most of the responses to this scene speak only about the sadness. In this instance, the visual rhetoric used would be that of pathos, defined by Aristotle as the ability to draw upon people's emotions. Many (including myself) felt incredibly disheartened to see the baby flamingo struggling and to know that it likely did not survive.

Even more outrage was generated in response to a specific scene in "Frozen World" showing walruses falling to their death on a rocky cliff. Toward the end of the episode, the viewers are introduced to "the largest gathering of walruses on the planet" (44:48). Over 100,000 walruses are gathered on a small rocky isle because their home, the sea ice, is vanishing and the place where they have found to rest is the closest area to their feeding grounds. There is barely any room on the rock, and the walruses often resort to climbing over others to get around, with those underneath at risk of being trampled to death. Some find more space by climbing high rocky cliffs, which is a challenge for such a large animal, one that is not familiar with and should never have to be on such landscapes. Once they reach the top, they inevitably need to go back down, but with their poor vision and inability to maneuver the rocky hill, many tumble to their death. It is around the 48-minute mark of the episode where viewers witness a large walrus falling to its death. The image is not easy to watch as we see the body turning over and over. Viewers then witness at least three or four different walruses falling and dying, finally landing in and among others with similar fates.

Soon after the episode was released and viewed by many, there was an outcry against the inclusion of the walrus scenes. It is arguably one of the most disturbing scenes in the series (Yong, 2019b). In response to the complaints, Netflix tweeted a warning to 
viewers listing the episodes and time stamps of scenes some viewers may find to be disturbing, two of which include the scene with the baby flamingo and the walrus scene. One viewer admitted that the series is "so beautiful and majestic" but that "the baby flamingo in episode one haunts me so I don't think I can handle the walruses" (OurPlanet, 2020). Others commented "this \#walrus scene was horrific," "the \#walrus footage is so tragic," and "watching episode 2 and one of the very rare occasions I am stunned by nature ... those poor walruses! I am beyond shocked" (OurPlanet, 2020). Parents of young children, in particular, warned other parents of the disturbing scenes, including Janice Duddy who recounted that when her son watched the scene, he started crying uncontrollably and it "made him fearful of other nature shows" (The Current, 2019). The director of the episode, Sophie Lanfear, confessed the sight was difficult to watch during filming. In Our Planet: Behind the Scenes (Cordey et al., 2019), viewers are offered a glimpse into the work and harrowing environments the film crew endures to capture the perfect shots. Toward the end of the episode, around the one-hour mark, Lanfear and her crew are pondering why the walruses are climbing on the rocky cliffs, and are shocked to see some fall to their deaths. Lanfear states "it is just so heartbreaking" (60:01) and wipes away tears. When asked about the reasons and importance of including the scene, Lanfear responded:

We thought long and hard about this sequence and what to show and whether to show it and as a filmmaker making a show on sea ice, essentially the whole film is about the ice and people understanding the importance of sea ice to our planet. And I think we felt that this sequence kind of sums up what the loss of sea ice, the set loss of sea ice, can have on some animals. And so, we just felt it was a very important thing to document really and the first people to do so. (The Current, 2019)

There have been many discussions about the inclusion of this image from the scientific community, many being skeptical about its relationship to climate change (Yong, 2019b). The reasons why walruses haul up on land, specifically, instead of on sea ice, is complex and there are multiple facets to consider but, for the purpose of this paper, the focus will be on the viewers' reactions to the images. Viewers such as Duddy state they understand Lanfear's intention in including this scene, but argue that, perhaps, the message was lost on viewers. Some viewers did pick up on Lanfear's suggestion and commented that the series is "glorious and heartbreaking to watch. Devastating to see the impact of \#climatechange on the \#walrus and other ice-dependent species" (OurPlanet, 2020). Similarly, another remarked that the "shows are fascinating, but at times difficult and heartbreaking to watch. The scenes of walrus with limited land due to \#GlobalWarming are horrific" and one viewer admitted that while the walrus scene was "sad" and "violent" it was also "necessary to understand the consequences of daily actions" (OurPlanet, 2020). One viewer felt that, overall, the "Frozen World" episode was the "most effective in getting enviro messages across" (OurPlanet, 2020). Audiences around the world reacted with great sympathy and sadness to this scene, in particular. The type of rhetoric used in this case is difficult to pinpoint. One could argue for the use of pathos since, as with the flamingo scene described above, the images do largely draw upon one's empathy. But as many viewers describe the scene as disturbing, one may also classify the rhetoric as apocalyptic, utilizing images containing messages of impending ecological crisis and depicting catastrophic effects (Cox, 2013). In this case, if current trends and behaviours with regard to the environment continue, then walruses will not have sea ice to rest on, will continue to seek 
out land, and will be in overcrowded environments that will result in more unnecessary walrus deaths. Yet, it is curious as to why exactly audiences reacted in such a way to this particular image when in the episode there are images of orca whales swimming after penguins, tossing them in the air to kill before eating them. Is it because audiences have seen the images of orca whales killing and eating penguins? Is it because we are more informed about the patterns and habits of certain animals more than others? Or is it because viewers were not expecting to witness such a graphic scene of many different walruses falling to their death in a series such as Our Planet? Do these types of images then distract viewers from the message? Many would agree these types of fear images are not typically used in documentaries or docuseries that are similar to Our Planet. In fact, it appears there was "a clear editorial decision to keep the "feel' of the main episodes similar to previous documentaries" (Jones, et al., 2019, p. 421). Therefore, I argue that it was not just the use of a certain sequence or use of images, but the shock was also a result of the viewers' expectation of this particular genre being disrupted.

\section{Discussion}

Throughout history, many forms of environmental media have been created to elicit social action, some of which manipulated the genre format. One example, while a print text but still pivotal for this discussion, is of Rachel Carson's Silent Spring (1962), which informs readers of the dangers of the chemicals used in pesticides-danger to both the environment and to people. Silent Spring was immensely popular and is still considered a key text today because it engages readers with relevant content. However, rather than relying on scientific jargon, Carson wrote the book as a narrative; the book, while factual, reads like a novel. It demonstrates how Carson's "use of imagery and emotion is almost perfectly judged" (Radford, 2011, para. 6), and how she is able to let the text present itself, allowing readers to draw their own opinions and conclusions. This may have been one of the reasons Silent Spring was so well received and why it raised people's awareness about the use of synthetic pesticides, such as dichlorodiphenyltrichloroethane (DDT) (Radford, 2011). This awareness, and the resulting outcry against the use of DDT, helped establish the US Environmental Protection Agency in 1970, which banned DDT in the US in 1972 (Paull, 2013). In this instance, the unexpected narrative style of Silent Spring could arguably be the reason why readers were encouraged to act.

Relating to documentaries, after his term ended in 2001, Al Gore, former vice president of the United States and avid environmentalist, commenced a lecture tour on the topic of climate change. These lectures became the basis for the documentary $A n$ Inconvenient Truth (Bender \& Guggenheim, 2006). Although it is not without criticism, one might argue this documentary helped to move environmental issues from complex ideas to providing accessible explanations of information around climate change. Gore is able to deliver his argument,

without being patronizing, boring or dry. He mixes in jokes . . . to keep you going between the beautiful but terrifying pictures of melting glaciers and disappearing forests. And the science is laid out flawlessly ... [he] lays out the evidence piece by comprehensible piece to build a conclusion that's hard to fault. (O'Hara, 2006, para. 3)

The documentary combines the use of science with elements of Gore's personal narrative, also drawing upon sublime and environmental nostalgia visual rhetoric. With the former, 
as noted earlier, images invite viewers to consider the beauty of nature and what might be lost should people not change their attitudes. Similarly, environmental nostalgia connects viewers to images that remind them of their past or personal experiences. An Inconvenient Truth also informs audiences of how people have caused environmental devastation, while at the same time showing how people can also be a part of the solution. This documentary moved environmental issues away from complex scientific perspectives and toward moral responsibility. It invited viewers to be part of the conversation to contribute to possible solutions (Johnston, 2013). The documentary "stands as a prototype of activist filmmaking" (Hachard, 2014, para. 3). An Inconvenient Truth, much like Carson's (1962) Silent Spring, had a "much greater impact on public opinion and public awareness of global climate change than any scientific paper or report" (Cook, 2016, para. 4).

Both Silent Spring and An Inconvenient Truth demonstrate the power that a single text can have in catalyzing public interest and action for change. What is worth noting, though, is how these two texts did not rely on the same representational patterns typical of these types of genres. In both cases, arguably, they were the first texts on these topics to engage the audience through narratives that are relatable and understandable to a lay person or someone who is not familiar with specific jargon. In the case of Silent Spring and An Inconvenient Truth, the manipulation of the genre is more nuanced and resulted in positive reactions from the public. Yet, the walrus scene was much more abrupt, much more striking as these types of images or apocalyptic visual rhetoric are rarely seen in genres typical of docuseries such as Our Planet. Thus, the audiences' responses and their reaction to images that disrupted their expectations of the genre is worth noting and investigating further, especially with regard to whether such reactions increase viewers' awareness and understanding of environmental issues and encourage acts of change.

With the disrupting walrus scene, one may argue that it is the use of apocalyptic visual rhetoric that provoked viewers' discontent, as typically these types of images are quite shocking. However, viewers' responses to apocalyptic images vary. For example, Lowe (2006) notes how the apocalyptic mode is often overused and may result in people feeling hopeless or apathetic about issues and has the potential to make viewers feel "change is impossible, rendering them and us as powerless" (Lowe, 2006, p. 6). But for some viewers, apocalyptic rhetoric can reignite awareness or perhaps even motivate a change in behaviour (Lowe, 2006). As Cox (2013) asks, "how do you raise awareness of future, serious effects from climate change without relying on visions of apocalypse?" (p. 66). With regards to viewers' reactions to various kinds of images (or any kind of rhetoric, really), there are indeed many factors at play, such as one's background experiences and personal preferences. Genre, as Frow (2006) notes, is a function of reading or viewing, and one's background experiences have an impact on how one might respond to texts or, in this case, the textual patterns or the use of images of a particular genre. Reader-response theorists also note how readers (or viewers, in this case) are engaged in a relationship with the text; they engage in a transaction (Hall, 1973; Iser, 1974; Rosenblatt, 1969). However, one does need to acknowledge the role of genres and how they have become forms that people recognize and often respond to in a particular way (Bawarshi \& Reiff, 2010), which would include one's expectations of a particular genre based on one's background experience and transactions with similar texts. That is, knowing that One Planet is narrated by David Attenborough, one will expect this docuseries to be similar to other productions and may even be labelled as particularly Attenborough-esque, which arguably do not 
include disturbing images such as walruses tragically falling to their deaths. If a viewer is not expecting this type of image from this type of documentary, could that not be shocking? Could this be the reason why viewers reacted even more strongly? With an increase in number of a variety of media formats, including the documentary, centred on informing the public about significant environmental issues, the larger question is: what happens when viewers' expectations of a genre are challenged? In other words, what happens when a trusted genre, such as a documentary or docuseries, implements visual rhetoric that disrupts the viewer's expectations? Does this change viewers' understanding of environmental issues? Of their willingness to act or change? Or do the images simply jar and deter viewers? In the case of the walruses, did this scene evoke a deeper level of concern for the environment among viewers, perhaps even motivating them change their behaviours? Or, were viewers simply shocked? While some viewer comments, as provided earlier, acknowledged the connection between climate change and the brutal consequences of the need for walruses to adapt, one even stated "let's stop retweeting and actually to try do something to help stop climate change" (OurPlanet, 2020). And so, the important question is whether they themselves enacted in this change? Or perhaps the larger question is whether or not viewers were fixated on the images as being too disturbing to truly consider the significant message the director was trying to relay and come up with solutions for change? While the above discussions regarding Silent Spring and An Inconvenient Truth do demonstrate a more subtle change in genre, I would argue that if the genre markers are more obviously shifted, this will have an effect on the ways viewers react, which could also impact their willingness to act in more eco-conscious ways.

\section{Conclusion}

As more and more people turn to the documentary as a source of information about issues related to the environment it becomes even more important to consider the nuanced play of images and the ways in which the genre and its representational patterns affect viewers. To date, the notion of multiliteracies has arguably centred on aspects related to technology, such as the ability to navigate different online platforms and, more recently, to combat deceptive media or disinformation. Yet, the original paper by the New London Group (1996) stresses the need for students to also maintain and continue to develop more traditional literacies as they relate to academic success and overall positive citizenship. However, since that article was published, even the notion of increasing students' cultural and linguistic awareness continues to shift greatly. And while there is a necessary focus on multimodal texts and multiple literacy practices, there is an obvious absence of the consideration of genre and its patterns and how they affect the meaningmaking process, especially if the viewers' expectations of a trusted genre are challenged. I contend that this becomes of particular concern when the shared information is related to a critical social justice issue. While Lanfear may have decided to purposefully include the jarring images of walruses falling to their deaths with the intent of encouraging viewers to think about climate change to possibly motivate them to alter their actions, the question is whether the end result was successful. While such images can catalyze discussion about environmental issues, the momentum, more often than not, dissolves as quickly as the discussion started; as with the case of One Planet. The larger question is whether viewers who did make connections to issues of climate change were motivated to change their behaviours or were mostly just drawn to the images at an empathetic level because, after 
all, we are all human. Thus, there needs to be more research examining viewer responses to different types of visual rhetorical modes in relation to genre expectations and how viewers may or may not be willing to act in more eco-conscious ways.

\section{References}

Ahn, C. (2018). Visual rhetoric in environmental documentaries [Unpublished doctoral dissertation]. University of British Columbia, Vancouver, BC.

Ahn, C. (2020). Considering the role of documentary media in environmental education. Journal of Canadian Curriculum Studies, 17(2), 67-79.

Ban, K. M. (May 2016). Secretary-General's remarks at climate action 2016 [as prepared for delivery]. https://www.un.org/sg/en/content/sg/statement/2016-0505/secretary-generals-remarks-climate-action-2016-prepared-delivery

Barnouw, E. (1993). Documentary: A history of the non-fiction film. Oxford University Press.

Barthes, R. (1981). Camera lucida: Reflections of photography. Hill and Wang.

Bawarshi, A. S., \& Reiff, M. (2010). Genre: An introduction to history, theory, research, and pedagogy. Parlor Press, LLC.

Bender, L. (Producer), \& Guggenheim, D. (Director). (2006). An inconvenient truth [Motion picture]. Paramount Classics

Bitzer, L. F. (1968). The rhetorical situation. Philosophy and Rhetoric, 1(1), 1-14.

Boykoff, M. T. (2007). Flogging a dead norm? Newspaper coverage of anthropogenic climate change in the United States and United Kingdom from 2003 to 2006. Area, 39(4), 470-482.

Carson, R. (1962). Silent spring. Houghton Mifflin Company.

Clay, J., Huertas, D., Anderson, A., Fothergill, A., Scholey, K. (Producers), Clay, J., Huertas, D., \& Anderson, A. (Directors). (2019). Our planet [Television series]. Netflix. https://www.netflix.com/ca/title/80049832

Cook, J. (2016). Ten years on: How Al Gore's "An Inconvenient Truth" made its mark. http://theconversation.com/ten-years-on-how-al-gores-an- inconvenient-truthmade-its-mark-59387

Cordey, H., Lanfear, S., Mallalieu, I., O’Donovan, K., Pearson, H. \& Sverdrup, G. (2019). Our planet: Behind the scenes [Television documentary]. Netflix.

Cox, R. (2013). Environmental communication and the public sphere. Sage Publications.

DuPré Pesmen, P. (Producer), \& Psihoyos, L. (Director). (2009). The cove [Documentary]. Diamond Doc Films.

Duvall, J. A. (2017). The environmental documentary: Cinema activism in the 21st century. Bloomsbury Academic.

Frow, J. (2006). Genre. Routledge.

Gold, J., \& Revill, G. (2004). Representing the environment. Routledge. https://doi.org/10.4324/9780203645987

Gronbeck, B. (1978). Celluloid rhetoric: On genres of documentary. In K. K. Campbell \& K. Hall Jamieson (Eds.), Form and genre: Shaping rhetorical action (pp. 139161). The Speech Communication Association.

Hachard, T. (2014, September 21). After "An Inconvenient Truth": The evolution of the "climate change film." The Guardian. 
https://www.theguardian.com/film/2014/sep/21/inconvenient-truth-evolutionclimate-change-film

Hackley, B. C. (2012). Rhetoric of social change in documentary film scores: An analysis of "The Cove" (Master's thesis). San Jose State University. http://scholarworks.sjsu.edu/cgi/viewcontent.cgi?article=7667\&context=etd these $\underline{\mathrm{S}}$

Hall, S. (1973). Encoding and decoding in the television discourse. [Paper for the Council of Europe Colloquy on "training in the critical reading of televisual language."] https://core.ac.uk/download/pdf/81670115.pdf

Hansen, A., \& Machin, D. (2013). Editor's introduction: Researching visual environmental communication. Environmental Communication, 7(2), 151-168.

Haraway, D. J. (2008). When species meet. Minneapolis, MN: University of Minnesota Press.

Helmers, M., \& Hill, C. A. (2004). Introduction. In C. A. Hill \& M. Helmers (Eds.) Defining visual rhetorics (pp. 1-4). Lawrence Erlbaum Associates.

Hill, C. A. (2004). The psychology of rhetorical images. In: C. A Hill \& M. Helmers (Eds.), Defining visual rhetorics (pp. 25-40). Lawrence Erlbaum Associates.

Iser, W. (1974). The implied reader: Patterns of communication in prose fiction from Bunyan to Beckett. The Johns Hopkins University Press.

Joffe, H. (2008). The power of visual material: Persuasion, emotion and identification. Diogenes, 55(1), 84-93.

Johnston, L. (2013, April 3). How An Inconvenient Truth expanded the climate change dialogue and reignited an ethical purpose in the United States. Georgetown University, Washington, D.C. https://repository.library.georgetown.edu/bitstream/handle/10822/558371/Johnsto n_geor getown_0076M_12090.pdf? sequence $=1$

Jones, J. P., Thomas-Walters, L., Rust, N. A., \& Veríssimo, D. (2019). Nature documentaries and saving nature: Reflections on the new Netflix series Our Planet. People and Nature, 1(4), 420-425.

Kara, S., \& Marcus, D. (2016). Introduction: Situating contemporary documentary. In: D. Marcus \& S. Kara. (Eds.), Contemporary documentary (pp. 1-6). Routledge.

Kitchell, M. (Producer/Director). (2012). A fierce green fire: The battle for a living planet [Documentary]. ZAP Zoetrope Aubry Productions.

Ladino, J. (2013). Working with animals: Regarding companion species in documentary film. In: S. Rust, S. Monani, \& S. Cubitt (Eds.), Ecocinema theory and practice (pp. 129-148). Routledge.

Lowe, T. D. (2006). Is this climate porn? How does climate change communication affect our perceptions and behaviour? Tyndall Centre for Climate Change Research. Working Paper 98. http://oldsite.tyndall.ac.uk/sites/default/files/wp98.pdf

Luke, A. (2015, June 5). DLC Talks: Luke \& Robinson 2015 Part 1. Faculty of Education Digital Literacy Centre, University of British Columbia. https://dlc.lled.educ.ubc.ca/2015/03/16/education-after-snowden-teaching-andlearning-about-the-new-information-order/

McLane, B. W. (2012). A new history of documentary film (2nd ed.). Continuum International Publish Group.

Miller, C. (1984). Genre as social action. Quarterly Journal of Speech, 70(2), 151-167. 
Murray, R. L., \& Heumann, J. K. (2014). Film and everyday eco-disasters. University of Nebraska Press.

Netflix. (n.d.). Our planet. https://www.netflix.com/ca/title/80049832

Nichols, B. (2010). Introduction to documentary. Indiana University Press.

Nissani, M. (1999). Media coverage of the greenhouse effect. Population and Environment, 21(1), 27-43.

O'Hara, H. (2006, September 15). An inconvenient truth review. [Review of the film "An Inconvenient Truth" by D. Guggenheim (Director)]. http://www.empireonline.com/movies/inconvenient-truth/review/

O’Neill, S., \& Nicholson-Cole, S. (2009). "Fear won't do it": Promoting positive engagement with climate change through visual and iconic representations. Science Communication, 30(3), 355-379.

Orr, D. W. (1990). Environmental education and ecological literacy. The Education Digest, 55(9), 49-53.

Our Planet (@OurPlanet2020), (2020, July 9), Our Planet [Twitter moment]. https://twitter.com/i/events/1281691668010475520?s=20

Paull, J. (2013). The Rachel Carson letters and the making of Silent Spring. Sage Open, $3(3), 1-12$.

Radford, T. (2011, September 30). Silent spring by Rachel Carson-review. [Review of the book Silent Spring, by Rachel Carson]. The Guardian.

https://www.theguardian.com/science/2011/sep/30/silent-spring-rachel-carsonreview

Rosenblatt, L. M. (1969). Towards a transactional theory of reading. Journal of Reading Behavior, 1(1), 31-49. https://doi.org/10.1080/10862969609546838

Schryer, C. (1994). The lab vs. the clinic: Sites of competing genres. In: A. Freedman \& P. Medway (Eds.), Genre and the new rhetoric (pp. 105-124). Taylor \& Francis.

Shapiro, A. (April 2019). "Our Planet" nature documentary addresses the 800-pound gorilla—human impact. National Public Radio (NPR).

https://www.npr.org/2019/04/15/713585983/our-planet-nature-documentaryaddresses-the-800-pound-gorilla-humanimpact?utm_source=twitter.com\&utm_medium=social\&utm_campaign=npr\&utm term=nprnews\&utm_content=20190415

Smith, N., \& Joffe, H. (2012). How the public engages with global warming: A social representations approach. Public Understanding of Science, 22(1), 16-32.

Sobel, D. (1998). Beyond ecophobia. Yes! [magazine]. https://web.archive.org/web/20191116232749/http:/www.yesmagazine.org:80/iss ues/education-for-life/803

Swain, K. A. (2012). Mass media roles in climate change mitigation. In: W.Y. Chen, J. Seiner, T. Suzuki, \& M. Lackner (Eds.), Handbook of Climate Change Mitigation (pp. 161-195). Springer US.

The Current. (April 2019). After complaints from parents, "Our Planet" director defends footage of walruses plummeting to their death. $C B C$ Radio. https://www.cbc.ca/radio/thecurrent/after-complaints-from-parents-our-planetdirector-defends-footage-of-walruses-plummeting-to-their-death-1.5098190

The New London Group. (1996). A pedagogy of multiliteracies: Designing social futures. Harvard Educational Review, 66(1), 60-93. 
UNESCO (1997). Educating for a sustainable future: A transdisciplinary vision for concerted action.

http://www.unesco.org/education/tlsf/mods/theme_a/popups/mod01t05s01.html

Yong, E. (April 2019a). Netflix's “Our Planet” says what other nature series have omitted. The Atlantic.

https://www.theatlantic.com/science/archive/2019/04/wildlife-series-finallyaddresses-elephant-room/586066/

Yong, E. (April 2019b). The disturbing walrus scene in "Our Planet." The Atlantic. https://www.theatlantic.com/science/archive/2019/04/why-are-walruses-walkingoff-cliffs/586510/

Author Biography

Claire Ahn is an Assistant Professor of Multiliteracies in the Faculty of Education at Queen's University. Claire's research is broadly focused on exploring how visual information is mediated across different platforms and how this informs our understandings of issues, events and of people. Claire is also interested in how youth take up visual information and how educators can better develop students' critical digital literacy skills. 